\title{
Epidemiological Patterns of Head Injury in Bauchi, North-Eastern Nigeria
}

\author{
Ogunleye Olabisi $\mathbf{0}^{1 *}$, Shuaibu Ibrahim $\mathbf{S}^{\mathbf{1}}$ and Obanife Henry $\mathbf{O}^{2}$ \\ ${ }^{1}$ Department of Surgery, Abubakar Tafawa Balewa University Teaching Hospital, \\ Bauchi, Bauchi State, Nigeria \\ ${ }^{2}$ Department of Surgery, University of Calabar, Calabar, Cross River State, Nigeria \\ *Corresponding Author: Ogunleye Olabisi O, Department of Surgery, Abubakar \\ Tafawa Balewa University Teaching Hospital, Bauchi, Bauchi State, Nigeria.
}

Received: October 06, 2020

Published: April 19, 2021

(C) All rights are reserved by Ogunleye Olabisi 0., et al.

\begin{abstract}
Introduction: Head injury is the leading cause of death and disability among young adults. It constitutes close to $50 \%$ of all injuries. Data have shown that a significant proportion of the world's population, over 57 million are living with neurological sequalae of head injury. The study aimed to describe the epidemiology of head injury in a center with no previous neurosurgical services in North Eastern Nigeria.

Materials and Methodology: A prospective study that involved all patients managed with head injury between September 2018 and August 2019. Demographic, clinical radiological details obtained and patients categorization made using Glasgow coma scale (GCS) and the treatment offered based it. The outcome was measured with Extended Glasgow Outcome Score (GOSE). Descriptive statistics were obtained Mean Standard deviation SD, Frequencies, Percentages.

Results: Eighty-four percent were males with male to female ratio of 5:1. The most prevalent cause of head injury was road traffic accident (89\%). Moderate of head injured patients were the majority (42\%) while 59\% of the patient has injury severity score (ISS) of $\geq 25$. Favourable outcomes were recorded in most of the patients (89\%).

Conclusion: The burden of head injury on patients, patient's relatives/care-givers and health care services in our environment is worrisome though our study recorded favourable outcomes in most of the patients. Public health awareness is the key to prevention. Keywords: Trauma; Head Injury; Pattern
\end{abstract}

\section{Introduction}

Head injury (HI) is defined as physical damage to the brain or skull caused by external forces [1]. It encompasses a wide variety of injuries with differing severities, ranging from trivial head wounds to traumatic brain injuries (TBIs).

Head injuries have been shown to constitute almost $50 \%$ of all injuries. Head injuries are a major cause of loss of life and disabilities among young adults [2-4]. Head injury has caused more than 57 million people in the whole world to be living with the neurological problem as sequalae of traumatic brain injury (TBI), in which 10 million people require hospital based care [5].
TBIs are significant causes of deaths and disability irrespective of age groups. Data from the epidemiological findings from the last ten years, have helped to put forth some effective preventive measures, such as the most appropriate health care provision for both acute care and rehabilitation of disabled survivors [6]. Head injury accounted for over $60 \%$ of in-hospital trauma deaths. TBI is higher in North America and Europe. On average, 2.8 million people had a TBI annually [6]. TBI also affected the economy of the countries, produced some financial losses, and reduced the productivity. Almost US\$60 billion was used to overcome the damages of TBI in year $2000[7,8]$. 
In Nigeria, head injury was observed to be the most common among all injuries [9]. An incidence rate of 2710/100,000 per year has been reported in a Nigerian study [10]. Among Malaysians, $4.75 \%$ of emergency patients had head injuries [11]. Another study stated that 69 million individuals worldwide were estimated to suffer from TBI [12]. The estimated population incidence of traumatic brain injury in the United States was $73.5 / 100,000$. It was reported that head injuries were most common among young adult $[13,14]$.

In the developing nations, including Nigeria, head injury is on the increase due to increasing incidence of road traffic accidents. Though other regions in our country has data on epidemiology of the traumatic brain injury. The commencement of standard neurosurgical services in this center to patients from various states across North Eastern part of the country will add to the data on epidemiology of traumatic brain injury in Nigeria.

\section{Aim of the Study}

The aim of this study was to investigate and describe the epidemiology of TBIs in our facility, which is in North Eastern Nigeria.

\section{Methodology}

This was a prospective study of patients admitted with traumatic brain injury who met inclusion criteria. Abubakar Tafawa Balewa University Teaching Hospital, Bauchi is a tertiary hospital located in Northeastern part of Nigeria with neurosurgical services being rendered to her primary and referred patients from within and neighboring states. The study was approved by the ethics committee of our institution, and the principles of the Helsinki declaration were observed during data collection.

The study included all patients with head injuries managed between September 2018-August 2019. The variables gathered for the study included patients' age, gender, etiology, time of presentation, the severity of injury (based on Glasgow coma scale, GCS), haematogical and radiological investigations, treatment offered and the outcome using Extended Glasgow Outcome Score (GOSE). The severity category was based on the assessment of GCS 14 - 15 was regarded as mild TBI, GCS 9 - 13 as moderate TBI, and GCS $\leq 8$ as severe TBI.

Data were analysed with the SPSS Version 20 software. Descriptive statistics were obtained Mean Standard deviation SD, Frequencies, Percentages.

\section{Results}

A total of 537 patients with head injury were managed within the study period. We observed that the Mean \pm SD of age was 37.02 \pm 17.21 . Figure 1 showed the age ranges of the study group, the age group with the highest number of patients $(20 \%)$ is $21-30 \mathrm{yrs}$ while those in the first five decades of life accounted for $80.4 \%$. There were 451 (84\%) males and 86 (16\%) females with ratio 5:1 (Table 1).

Table 1 showed that $83.3 \%$ of the patients presented primarily to our facility, Car was the major mode of transportation of these patients $(76.5 \%)$ and most of the patients $(74.7 \%)$ presented within the first $12 \mathrm{hrs}$ of the injury.

\begin{tabular}{|l|c|}
\hline Variables & N (\%) \\
\hline Gender & $451(84)$ \\
Female & $86(16)$ \\
\hline Mode of presentation & \\
Referral & $87(16.2)$ \\
Primary & $450(83.8)$ \\
\hline Mode of transportation & \\
Tricycle & $54(10.1)$ \\
Van & $21(3.9)$ \\
Car & $411(76.5)$ \\
Ambulance & $51(9.5)$ \\
\hline Time of presentation & \\
$<12$ hrs & $401(74.7)$ \\
$>12$ - 24hrs & $80(14.9)$ \\
$>24 h r s$ & $56(10.4)$ \\
\hline
\end{tabular}

Table 1: Demographic and basic variables of patients in this study.

\section{In-Hospital clinical assessments' findings}

Road traffic accident accounted for $84.9 \%$ of all the causes of head injuries in this study, assault was second with $6.1 \%$ while $2 \%$ was due to Gunshot (Figure 2). The accidents that were related to motor vehicular accident, about $41 \%$ were Car passengers, while those related with Motorcycle, motorcyclist and motorcycle passenger were affected equally with $19 \%$ each (Figure 3 ). There were (134) 25\% mild, 223 (41.5) moderate and 180 (33.5) severe head injuries. Three hundred and fourteen patients had injury severity 
score (ISS) $\geq 25$ while Brain CT Rotterdam score of $\geq 3$ was seen in 192 (35.8\%) patients as shown in table 2.

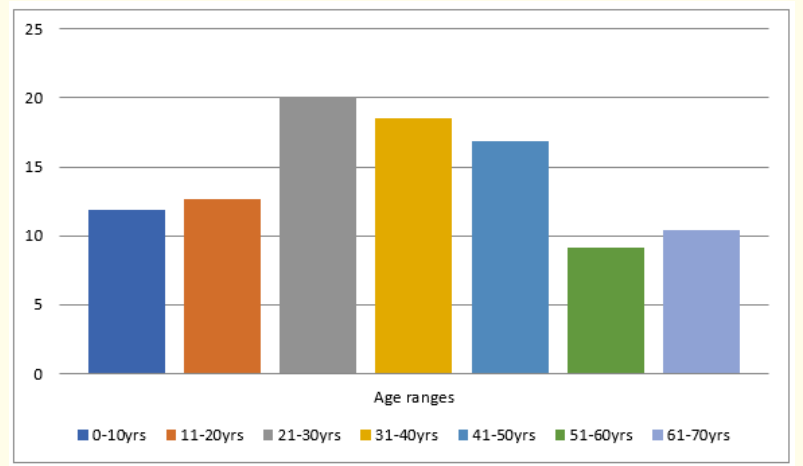

Figure 1: Age ranges of the head injured patients.

\section{IN-Hospital care and outcomes}

Four hundred and forty-four patients (82.7\%) were managed non-operatively while 93 (17.3\%) patients had operative intervention. The outcomes in this study were measured using Extended Glasgow outcome score (GOSE) which showed 61 (11\%) had poor outcome (Death, vegetative, lower and upper disability) and 476 (89\%) had good outcome (moderate and full recovery) as shown in table 3.

\begin{tabular}{|l|c|}
\hline Variables & N (\%) \\
\hline Glasgow Coma Score (GCS) & \\
Mild (13-15) & $134(25)$ \\
Moderate (9-12) & $223(41.5)$ \\
Severe (3-8) & $180(33.5)$ \\
\hline Injury Severity Score (ISS) & \\
ISS 1-24 & $223(41.5)$ \\
ISS $\geq 25$ & $314(58.5)$ \\
\hline Brain CT Rotterdam Score & \\
$1-2$ & $345(64.2)$ \\
$\geq 3$ & $192(35.8)$ \\
\hline
\end{tabular}

Table 2: Severity of the injury.

\begin{tabular}{|l|c|c|}
\hline \multicolumn{2}{|c|}{ Outcome(GOSE) } & $\begin{array}{c}\text { Proportions } \\
\text { N = 537 (\%) }\end{array}$ \\
\hline \multirow{4}{*}{$\begin{array}{l}\text { Poor Out- } \\
\text { comes }\end{array}$} & Death & $55(10)$ \\
\cline { 2 - 3 } & Vegetative & $0(0)$ \\
\cline { 2 - 3 } & Upwer severe disability(LSD) & $6(1)$ \\
\cline { 2 - 3 } & Lower moderate disability(LMD) & $81(15)$ \\
\cline { 2 - 3 } $\begin{array}{l}\text { Good Out- } \\
\text { comes }\end{array}$ & Upper moderate disability(UMD) & $36(7)$ \\
\cline { 2 - 3 } & Lower good recovery(LGR) & $85(16)$ \\
\cline { 2 - 3 } & Upper good recovery(UGR) & $274(51)$ \\
\hline
\end{tabular}

Table 3: Outcomes of head injuries. GOSE: Extended Glasgow Outcome Score.

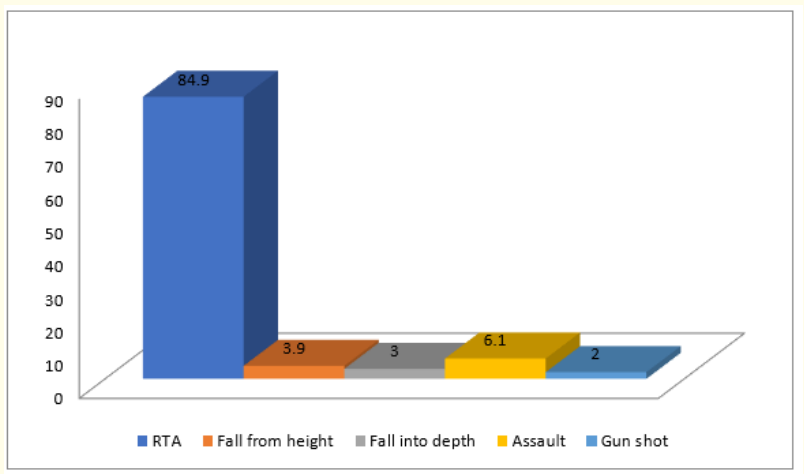

Figure 2: Aetiology of head injury.

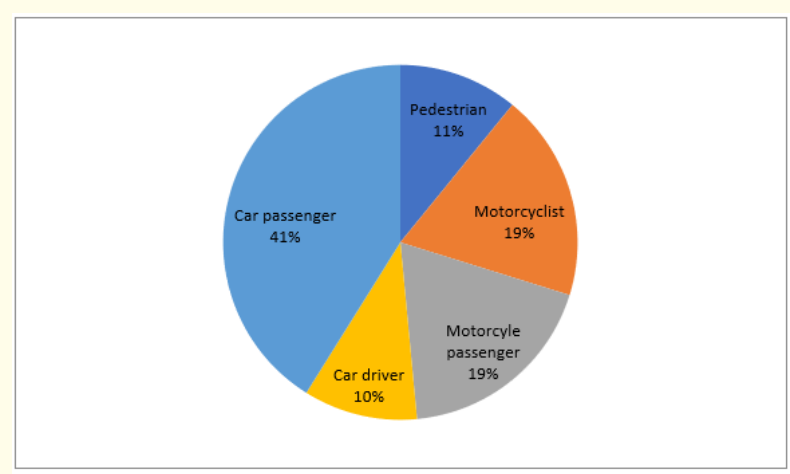

Figure 3: Categorization of road traffic accident's victims. 


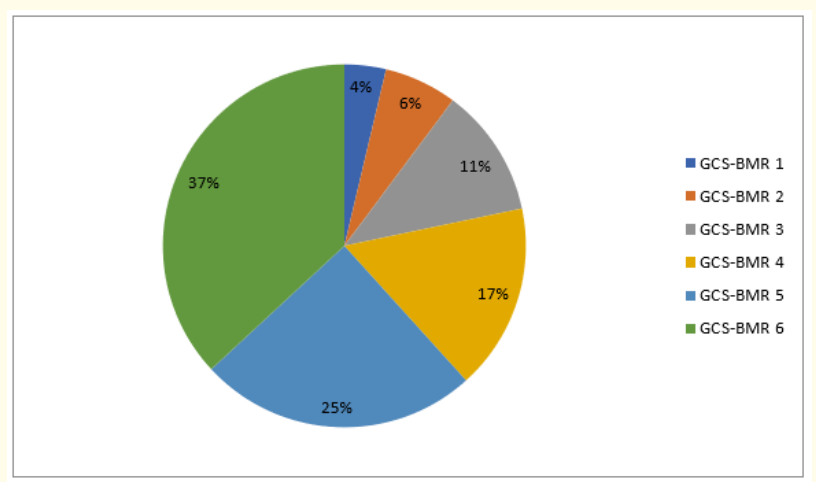

Figure 4: Pattern of Best Motor Response of Glasgow Coma Score (GCS-BMR).

\section{Discussion}

Head injury is now an emerging epidemic and it is growing public health concern. The consequences of head injury among patients and their relatives are devastating, these challenges ranges from emotional, psychological and financial burden on the part of the caregivers' while residual disabilities and poor quality of life by the survivors.

The majority of the patients from our study were young adults in their first five decades of life, which is the productive age. These findings are comparable with previous studies that reported high incidence of head injuries in young adults $[9,10,15-18]$. The peak incidence of head injury in this study was in 21 - 30 years which is in contrast with US study that reported high incidence among 15 19 years. Male preponderance of $5: 1$ as seen was in keeping with report from other studies [6,10,15-18]. In our settings, males are the breadwinner while the young adults represent the economically active population and because of these, they are more engaged in activities involving movement from one place to another and participate in high risk activities which includes car or motorcycle riders. With the recent increase in insecurities; insurgency, banditry etc, they are more predisposed to having head injury than any other group of the population.

Road traffic accident was found to be the most prevalent cause of head injuries in our study which is similar to findings in our previous studies within and outside our countries [10,14,16,18-21]. However, these findings were in variance from reports from developed countries, where fall was reported to be the commonest cause of head injuries [17,22-24]. This disparity in findings could be due to difference in geographical location, lower rate of RTAs, good road networks, well developed and organised transport system and good observance of traffic rules. In our study area, the bad road networks, poorly developed transport system and poor compliance with the standard traffic measures have increased the risks of head injuries. Assault, fall, gunshot were the other causes of head injuries observed which have been reported in other studies $[6,10,18,19,22,25]$. Assault and gunshot injuries are on the increase in our environment, this is not surprising due to increase in waves of insurgencies, banditry, communal and interpersonal related violence experiencing.

Motor vehicular accidents were leading cause of road traffic accidents leading to head injuries in this study and other similar studies across the globe $[16,25,26]$. This finding is in variance with the study by Emejulu., et al. in South Eastern part our country which reported motorcycle accidents as the commonest cause of road traffic accidents [10]. Pedestrian and fall (from height or into depth) related head injuries were common among children, this finding in our study is in conformity with studies by Emejulu., et al. [10] and Sharma., et al. [27]. It is worrisome that children are most affected in pedestrians and fall related head injuries while this could be attributed to various factors; poor supervision, negligence of parents and caregivers, poor parental care and street hawking/begging. Other factors proffered to the involvement of children in pedestrians related road traffic accidents includes; risk behaviours, immature cognitive functions and lack of physical coordination $[28,29]$.

The most prevalent head injury in this study is Moderate head injury (41\%) which is in contrast with report from some studies which have reported Mild head injury as the most prevalent $[10,18,30]$ while Ibrahim., et al. reported severe head injury as the most prevalent in their study [31]. Though more studies have shown higher prevalence of mild head injury than any other types of head injury, these disparities across studies may be difficult to explain but different geographical region and degree of impact/ mechanism of injury may be responsible.

Our study fatality rate of $10 \%$ falls within the $19.8 \%, 5.5 \%$ and $6.8 \%$ fatality rates of three studies conducted in another region of our country $[10,15,18]$. East African study by Chalya., et al. reported fatality rate of $11.2 \%$ which is also comparable with our find- 
ings. Surprisingly another study from East Africa reported a fatality rate of $56.2 \%$ [32]. It is worth to note that all the studies that reported comparable fatalities with our study had mild head injury as the most prevalent head injury while the high fatality rate from other study can be explained by severity of head injury and other patients' characteristics.

\section{Conclusion}

The risk factors for head injury in North Eastern part of Nigeria includes; male gender, young adults under 50yrs, road traffic accidents, insurgencies, farmer-herders' crisis ethnic/communal and interpersonal violence. Road traffic accident is the major causes of head injury. However, Motor vehicular, motor cycle and pedestrians related accidents are in order of most to less prevalent categories in road traffic accidents. The most active and productive adult in our environment were mostly affected with attending economic burden in the society. Our study recorded significant favourable outcomes, while our morbidity and mortality were comparable to findings of studies from other regions in our country.

The need for concerted public health efforts by the government and non-government organisations should be activated to prevent head injury, the leading cause of death and disability among the productive age groups in our society. Advocacy, enforcement of road safety rules and provision of good road infrastructure and standard public transport system are the keys to curb this scourge in our environment.

\section{Conflict of Interest}

No conflict of interest.

\section{Bibliography}

1. Barr RM., et al. "Craniofacial trauma”. In: Brant WE, Helms CA, editors. Fundamentals of Diagnostic Radiology. $4^{\text {th }}$ edition. Philadelphia: Wolters Kluwer.

2. Sharma B and Lawrence DW. "Top-cited articles in traumatic brain injury". Frontiers in Human Neuroscience 8 (2014): 4549.

3. Dawodu ST. "Traumatic brain injury (TBI)—Definition, Epidemiology, Pathophysiology" (2021).

4. Andelic N. "The epidemiology of traumatic brain injury". The Lancet Neurology 12.1 (2013): 28-29.
5. Kimbler DE., et al. "Concussion and the adolescent athlete". Journal of Neuroscience Nursing 43.6 (2011): 286-290.

6. Jennett B. "Epidemiology of head injury". Journal of Neurology, Neurosurgery and Psychiatry 60.4 (1996): 362-369.

7. National Vital Statistics System (NVSS), 2006-2010. Data source is maintained by the CDC National Center for Health Statistics.

8. National Hospital Discharge Survey (NHDS). National Hospital Ambulatory Medical Care Survey (NHAMCS), 2010 National vital statistics system (NVSS), 2010. All data sources are maintained by the CDC National Center for Health Statistics (2010).

9. Adeleye AO and Ogun MI. "Clinical epidemiology of head injury from road-traffic trauma in a developing country in the current era". Frontiers in Neurology 8 (2017).

10. Emejulu JK., et al. "Traumatic brain injury in the accident and emergency department of a tertiary hospital in Nigeria". East and Central African Journal of Surgery 15 (2010): 28-38.

11. Rohana J., et al. "Epidemiology of head injury in Malaysian children: a hospital-based study". Medical Journal of Malaysia 53.3 (1998): 217-222.

12. Dewan MC., et al. "Estimating the global incidence of traumatic brain injury”. Journal of Neurosurgery 5 (2015): 1-18.

13. Reid SR., et al. "The epidemiology of pediatric traumatic brain injury in Minnesota". JAMA Pediatrics 155.7 (2001): 784-789s.

14. Brudvik C. "Child injuries in Bergen, Norway". Injury 31.10 (2000): 761-767.

15. Emejulu JKC and Malomo O. "Head trauma in a newly established neurosurgical centre in Nigeria". East and Central African Journal of Surgery 13 (2008): 86-93.

16. Chalya PL., et al. "Aetiological spectrum, injury characteristics and treatment outcome of head injury patients at Bugando Medical Centre in north-western Tanzania". Tanzania Journal of Health Research 13 (2011): 93-102.

17. Thurman D and Guerrero J. "Trends in hospitalization associated with traumatic brain injury". JAMA 282 (1999): 954-957.

18. Bock-Oruma AA., et al. "Pattern of head injury in the emergency department of the Delta state university teaching hospital, Oghara, Nigeria". British Journal of Medicine and Medical Research 15 (2016): 1-6. 
19. Jasper US., et al. "The epidemiology of hospital-referred head injury in Northern Nigeria". Journal of Scientific Research and Reports 3 (2014): 2055-2064.

20. Laleef $\mathrm{OA}$ and Abedayo 0. "Epidemiology of severe injury in a Nigerian Hospital”. Nigerian Journal of Orthopedic Trauma 6 (2007): 67-69.

21. Yattoo GH and Tabish A. "The profile of head injuries and traumatic brain injury deaths in Kashmir". Journal of Trauma Management Outcome 2 (2008): 5.

22. Shivaji T., et al. "The epidemiology of hospital treated traumatic brain injury in Scotland”. BMC Neurology 14 (2014): 2.

23. Stead LG., et al. "TBI surveillance using the common data elements for traumatic brain injury: A population study". International Journal of Emergency Medicine 6 (2013): 5.

24. Ingebrigsten T., et al. "The epidemiology of hospital-referred head injury in northern Norway". Neuroepidemiology 17 (1998): 139-146.

25. Adeolu AA., et al. "Etiology of head injuries in Southwestern Nigeria: A public health perspective". Internet Journal of Epidemiology 2 (2004).

26. Yates PJ., et al. "An epidemiological study of head injuries in a UK population attending an emergency department". Journal of Neurology, Neurosurgery and Psychiatry 77 (2006): 669701.

27. Sharma BR., et al. "Patterns of fatal head injury in road traffic accidents". Bahrain Medical Bulletin 25 (2003): 22-25.

28. Schwebel DC and Bounds ML. "The role of parents and temperament on children's estimation of physical ability: Links to unintentional injury prevention". Journal of Pediatric Psychology 32 (2007): 517-516.

29. Barton BK and Schwebel DC. "The roles of age, gender, inhibitory control and parental supervision in children's pedestrian safety". Journal of Pediatric Psychology 32 (2007): 517-526.

30. J Leitgeb., et al. "Glasgow Coma Scale score at intensive care unit discharge predicts the 1-year outcome of patients with severe traumatic brain injury". European Journal of Trauma and Emergency Surgery 39.3 (2013): 285-292.

31. Ibrahim Alnaami., et al. "Patterns, Types, and Outcomes of Head Injury in Aseer Region, Kingdom of Saudi Arabia”. Neuroscience Journal (2019).
32. Mwang'ombe NJ and Kiboi J. "Factors influencing the outcome of severe head injury at Kenyatta National Hospital". East African Medical Journal 78 (2001): 238-241.

\section{Assets from publication with us}

- Prompt Acknowledgement after receiving the article

- Thorough Double blinded peer review

- Rapid Publication

- Issue of Publication Certificate

- High visibility of your Published work

Website: www.actascientific.com/

Submit Article: www.actascientific.com/submission.php Email us: editor@actascientific.com

Contact us: +919182824667 